\title{
SigC sigma factor is involved in acclimation to low inorganic carbon at high temperature in Synechocystis sp. PCC 6803
}

\author{
Correspondence \\ Taina Tyystjärvi \\ taityy@utu.fi
}

Received 10 July 2009

Revised 28 August 2009

Accepted 31 August 2009

\author{
Liisa Gunnelius, Ilona Tuominen, Susanne Rantamäki, Maija Pollari, $†$ \\ Virpi Ruotsalainen,‡ Esa Tyystjärvi and Taina Tyystjärvi
}

\author{
Plant Physiology and Molecular Biology, Department of Biology, University of Turku, FI-20014 \\ Turku, Finland
}

\section{INTRODUCTION}

Cyanobacteria are a group of evolutionarily ancient eubacteria that perform oxygenic photosynthesis, like higher plants and algae. According to the endosymbiosis theory, cyanobacteria are progenitors of plant chloroplasts. The ability of cyanobacteria to survive under a range of different environmental stress conditions makes them valuable model organisms for studies of molecular mechanisms of acclimation. In particular, the unicellular cyanobacterium Synechocystis sp. PCC 6803 (hereafter referred to as Synechocystis) has been extensively used in gene expression studies under a variety of different stress conditions (Huang et al., 2002; Suzuki et al., 2005; Osanai et al., 2006; Singh et al., 2006; Slabas et al., 2006; Tuominen et al., 2008). These and other studies have demonstrated that acclimation to changing environmental conditions requires changes in gene expression over a wide range of different functions. The sigma $(\sigma)$ subunit of RNA polymerase holoenzyme is a key

†Present address: VTT Technical Research Centre of Finland, FI-02044 Espoo, Finland.

$\ddagger$ Present address: Faculty of Biosciences, Natural Product Research Laboratories, University of Joensuu, Fl-80101 Joensuu, Finland.

Abbreviations: chl a, chlorophyll a; DCMU, 3-(3',4'-dichlorophenyl)-1,1dimethylurea; PPFD, photosynthetic photon flux density; PSIl, photosystem II. determinant of promoter recognition and transcription initiation in eubacteria, and replacement of a $\sigma$ factor in RNA polymerase holoenzyme with another one switches the transcription pattern (Wösten, 1998).

The genome of Synechocystis contains nine genes encoding $\sigma$ factors (Kaneko et al., 1996). The primary $\sigma$ factor SigA is essential for cell viability (Imamura et al., 2003). The sigB, sigC, sigD and sigE genes encode group $2 \sigma$ factors that closely resemble the SigA factor but are not essential for cell viability (Pollari et al., 2008). Recent studies show that group $2 \sigma$ factors are important for acclimation of cyanobacteria to suboptimal conditions (Muro-Pastor et al., 2001a; Imamura et al., 2003; Osanai et al., 2005, 2006; Singh et al., 2006; Tuominen et al., 2003, 2006, 2008; Foster et al., 2007; Pollari et al., 2008, 2009). The sigF, sigG, sigH and sigI genes of Synechocystis encode alternative $\sigma$ factors. The SigF factor is important for pilus formation and cell motility (Bhaya et al., 1999; Asayama \& Imamura, 2008), and sigG is known to be an essential gene (Matsui et al., 2007), but otherwise the physiological roles of the alternative $\sigma$ factors remain to be elucidated.

The temperature optimum of Synechocystis is $30-32{ }^{\circ} \mathrm{C}$, but the cells can grow at temperatures ranging from 15 to $43{ }^{\circ} \mathrm{C}$ (Inoue et al., 2001). For short periods, Synechcystis cells can tolerate temperatures up to $50{ }^{\circ} \mathrm{C}$ (Inoue et al., 
2001), and exposure to non-lethal high temperature improves the overall thermotolerance of Synechocystis (Nishiyama et al., 1999; Lee et al., 2000). Photosynthesis is a heat-sensitive process, with the oxygen-evolving complex of photosystem II (PSII) being regarded as the most heat-sensitive component (Mamedov et al., 1993).

The processes of acclimation to high temperature have only been partly resolved in Synechocystis. An immediate response to high temperature is the transient production of heat-shock proteins. The histidine kinase Hik34 is a component of a negative regulatory pathway of some heatshock genes (Suzuki et al., 2005; Slabas et al., 2006), and the CIRCE/HrcA system is involved in the regulation of the groESL1 operon and the groEL2 gene encoding heat-shock proteins (Nakamoto et al., 2003; Singh et al., 2006). The SigB factor has a crucial role in heat-shock responses and acquired thermal tolerance in Synechocystis, as it positively regulates the expression of heat-shock genes (Singh et al., 2006; Tuominen et al., 2006).

We recently noticed that another group $2 \sigma$ factor, the SigC factor, is also involved in high-temperature responses (Tuominen et al., 2008). However, the expression of heatshock genes was not altered in the $\Delta$ sigC strain. In this study, we further investigated heat acclimation in Synechocystis. One consequence of high temperature is that less inorganic carbon is available because the solubility of $\mathrm{CO}_{2}$ decreases with increasing temperature. Our results suggest that the SigC factor is required for adjustment of photosynthesis under high-temperature conditions.

\section{METHODS}

Bacterial strains. The glucose-tolerant strain Synechocystis sp. PCC 6803 was used as the control strain (CS) and the construction of the $\Delta$ sigC strain has been described previously (Tuominen et al., 2008). The BG-11 plates for the $\Delta$ sigC strain were supplemented with $50 \mu \mathrm{g}$ kanamycin $\mathrm{ml}^{-1}$, but no antibiotics were added to liquid cultures.

Growth measurements. Synechocystis cells were grown in BG-11 medium supplemented with $20 \mathrm{mM}$ HEPES- $\mathrm{NaOH}, \mathrm{pH} 7.5$, at $32{ }^{\circ} \mathrm{C}$ under the continuous photosynthetic photon flux density (PPFD) of $40 \mu \mathrm{mol} \mathrm{m}{ }^{-2} \mathrm{~s}^{-1}$. The cultures were shaken at 90 r.p.m. in a growth chamber at ambient air conditions. Growth was monitored by measuring $\mathrm{OD}_{730}$ with a spectrophotometer (Lambda Bio, Perkin Elmer). Samples were diluted with BG-11 before measurements so that the $\mathrm{OD}_{730}$ did not exceed 0.4, and the dilutions were accounted for in the calculation of results. One $\mathrm{OD}_{730}$ unit corresponds to $4 \times 10^{6}$ cells $\mathrm{ml}^{-1}$ in both strains.

For $\mathrm{CO}_{2}$ treatments, $\mathrm{OD}_{730}$ was set to 0.1 , and $30 \mathrm{ml}$ cell cultures were stirred in $100 \mathrm{ml}$ Erlenmeyer flasks inside a plexiglass box under the PPFD of $40 \mu \mathrm{mol} \mathrm{m} \mathrm{m}^{-2} \mathrm{~s}^{-1}$ at $32{ }^{\circ} \mathrm{C}$. The box was filled under slight overpressure with a gas mixture containing, like air, $79 \% \mathrm{~N}_{2}$ and $21 \% \mathrm{O}_{2}$, but only 30 p.p.m. $\mathrm{CO}_{2}$ (AGA). In control experiments, the box was filled with normal air ( 300 p.p.m. $\left.\mathrm{CO}_{2}\right)$.

At the start of the heat experiments, $\mathrm{OD}_{730}$ was set to 0.14 and growth was monitored at $43{ }^{\circ} \mathrm{C}$ under the PPFD of $35 \mu \mathrm{mol} \mathrm{m} \mathrm{m}^{-2} \mathrm{~s}^{-1}$. The $\mathrm{pH}$ of BG-11 medium was set to $6.7,7.5$ or 8.3 with 20 mM HEPES$\mathrm{NaOH}$, as indicated. The $\mathrm{pH}$ of the growth medium was measured after the growth period and was found to remain constant. In some experiments, $5 \mathrm{mM}$ glucose, $0.1 \mathrm{mM}$ cyclic adenosine $3^{\prime}, 5^{\prime}$-monophosphate (cAMP), $20 \mathrm{mM}$ 2-oxoglutarate, $20 \mathrm{mM}$ pyruvate or $20 \mathrm{mM}$ succinate was added, as indicated. To follow the recovery of the cells from high-temperature treatments, cell cultures were transferred to standard growth conditions.

Determination of CAMP content. Cells $\left[10 \mu \mathrm{g} \mathrm{ml}^{-1}\right.$ chlorophyll $a$ (chl a)] were heat-treated at $43{ }^{\circ} \mathrm{C}$ for $0,1,24$ or $72 \mathrm{~h}$. cAMP was isolated as described by Terauchi \& Ohmori (1999), and cAMP concentrations were measured using a cAMP Biotrak enzyme immunoassay system (Amersham).

Determination of photosynthetic activity in vivo. The $\mathrm{OD}_{730}$ of the cell culture was set to 0.14 and cells were incubated at $43{ }^{\circ} \mathrm{C}$ under a PPFD of $35 \mu \mathrm{mol} \mathrm{m} \mathrm{m}^{-2} \mathrm{~s}^{-1}$. The $\mathrm{pH}$ of the growth medium was set to 6.7, 7.5 or 8.3 with $20 \mathrm{mM}$ HEPES-NaOH, as indicated. Aliquots of $1 \mathrm{ml}$ were withdrawn after $1,13,16,18,44,56,75$ or $95 \mathrm{~h}$ of incubation at $43{ }^{\circ} \mathrm{C}$, the light-saturated rate of oxygen evolution was measured with an oxygen electrode (Hansatech) at $43{ }^{\circ} \mathrm{C}$, and the $\mathrm{OD}_{730}$ of each sample was measured. Photosynthetic activity was then calculated as $\mu \mathrm{mol} \mathrm{O}_{2}$ produced $\mathrm{h}^{-1}(\mathrm{ml} \text { cell culture })^{-1}$ at $\mathrm{OD}_{730}=1$. As a control, the light-saturated rate of oxygen evolution at $32{ }^{\circ} \mathrm{C}$ was determined for cells grown under standard growth conditions at $32{ }^{\circ} \mathrm{C}$.

Decay of chl $a$ fluorescence yield after a single-turnover flash was measured with an FL 200 fluorometer (P.S. Instruments) in the absence and presence of $10 \mu \mathrm{M} \quad 3$-( $3^{\prime}, 4^{\prime}$-dichlorophenyl)-1,1dimethylurea (DCMU). The $1 \mathrm{ml}$ samples (containing $4.4 \mu \mathrm{g} \mathrm{chl} a$ ) were measured at $32{ }^{\circ} \mathrm{C}$ (samples from growth conditions) or at $43{ }^{\circ} \mathrm{C}$ (samples from cultures treated at $43{ }^{\circ} \mathrm{C}$ for 1 or $24 \mathrm{~h}$ ). The samples were first dark-incubated for $5 \mathrm{~min}$. Each fluorescence relaxation curve started with measurement of the initial fluorescence level with low-intensity probe flashes, then a strong flash was fired and fluorescence intensity was probed with weak probe flashes. The time delay between the probe flashes increased exponentially in the course of each curve. In measurements done in the absence of DCMU, the first probe flash was fired $150 \mu$ s after the strong flash and eight probe flashes were fired per decade of time unit. Only two probe flashes per decade were used in the presence of DCMU.

The fluorescence curves were processed by subtracting initial fluorescence and normalizing the curves by dividing by the value obtained with the first probe flash after the strong flash. Analysis of the decay of chl $a$ fluorescence yield after the strong flash was done using four first-order component reactions. Two fast components represent populations of PSII in which the primary quinone $\left(\mathrm{Q}_{\mathrm{A}}^{-}\right)$is oxidized by electron transfer to the secondary quinone $\left(\mathrm{Q}_{\mathrm{B}}\right)$ or $\mathrm{Q}_{\mathrm{B}}^{-}$(submillisecond component), and PSII with an empty $\mathrm{Q}_{\mathrm{B}}$ site (millisecond component) (see Tyystjärvi \& Vass, 2004). Two slow components represent inactive PSII centres, one component tentatively representing PSII centres that oxidize $\mathrm{Q}_{\mathrm{A}}$ via the recombination reactions $S_{2 / 3} Q_{A}^{-} \rightarrow S_{1 / 2} Q_{A}$ (1-5 s component), another component representing centres undergoing very slow oxidation of $\mathrm{Q}_{\mathrm{A}}^{-}$ (component with $\sim 20 \mathrm{~s}$ half-time).

Western blotting. Changes in the amount of the SigC factor were followed for $72 \mathrm{~h}$ at $43{ }^{\circ} \mathrm{C}$ in the cell cultures grown in BG-11 medium buffered with $20 \mathrm{mM}$ HEPES at $\mathrm{pH} 6.7,7.5$ or 8.3. After the treatments, cells were rapidly cooled and collected by centrifugation at $10000 \mathrm{~g}$ for $5 \mathrm{~min}$ at $4{ }^{\circ} \mathrm{C}$. The cell pellets were washed with icecold STNE buffer (0.4 M sucrose, $10 \mathrm{mM}$ Tris/HCl, pH 8.0, $10 \mathrm{mM}$ $\mathrm{NaCl}, 20 \mathrm{mM}$ sodium EDTA), and resuspended in $75 \mu$ STNE buffer. One-third volume of acid-washed glass beads (Sigma) was added and cells were broken by vortexing three times for $2 \mathrm{~min}$. Glass beads and unbroken cells were removed by centrifugation at $4000 \mathrm{~g}$ for $4 \mathrm{~min}$ at $4{ }^{\circ} \mathrm{C}$. Membranes were collected by centrifugation at $19500 \mathrm{~g}$ for $15 \mathrm{~min}$ at $4{ }^{\circ} \mathrm{C}$. The supernatant was collected and recentrifuged for $15 \mathrm{~min}$ at $19500 \mathrm{~g}$ at $4{ }^{\circ} \mathrm{C}$ to get the soluble protein fraction. The concentrations of proteins were measured with the Lowry protein 
assay (Bio-Rad). Proteins $(50 \mu \mathrm{g})$ were separated by using $10 \%$ NEXT GEL SDS-PAGE according to the manufacturer's instructions (Amresco). After electrophoresis, separated proteins were transferred to Immobilon-P membranes (Millipore). A SigC specific antibody was raised against amino acids 392-404 of Synechocystis SigC protein (Innovagen), and the CDP Star chemiluminescence kit (New England Biolabs) was used for detection in Western blotting. The SigC antibody was found to recognize a protein of $\sim 51 \mathrm{kDa}$ and another one at $60 \mathrm{kDa}$. The $51 \mathrm{kDa}$ protein corresponded to the expected molecular mass of SigC, and was found to be missing from the $\Delta$ sigC strain. The $60 \mathrm{kDa}$ band, on the other hand, was too big to be SigC, and was found in the $\Delta$ sigC samples. These data indicate that the $51 \mathrm{kDa}$ band is $\mathrm{SigC}$, while the $60 \mathrm{kDa}$ band is non-specific.

\section{RESULTS AND DISCUSSION}

\section{Addition of organic carbon sources does not restore the growth of the $\Delta$ sigC strain at $43{ }^{\circ} \mathrm{C}$}

We have previously shown that the $\Delta$ sigC strain is barely able to grow at $43{ }^{\circ} \mathrm{C}$ under normal air (Tuominen et al.,
2008). The equilibrium concentration of $\mathrm{CO}_{2}$ at $43{ }^{\circ} \mathrm{C}$ can be estimated to be $76 \%$ of the concentration at $32{ }^{\circ} \mathrm{C}$ (calculated by using the temperature dependency of Henry's law for $\mathrm{CO}_{2}$ ). Thus, an inevitable consequence of high temperature is that less inorganic carbon is available in the growth medium. Interestingly, addition of inorganic carbon in the form of $3 \% \mathrm{CO}_{2}$ to the growth chamber partially restores the growth of the $\Delta$ sigC strain at $43{ }^{\circ} \mathrm{C}$ (Tuominen et al. 2008).

At the standard growth temperature, $32{ }^{\circ} \mathrm{C}$, addition of the organic carbon sources $5 \mathrm{mM}$ glucose (Pollari et al., 2008) or $20 \mathrm{mM}$ pyruvate (Fig. 1a) enhanced growth of both the control and the $\Delta$ sigC strains. However, addition of glucose or pyruvate did not enhance growth at $43{ }^{\circ} \mathrm{C}$ (Fig. 1b). After 1 day of treatment at $43{ }^{\circ} \mathrm{C}$, both strains recovered well if cell cultures were transferred to standard growth conditions (Fig. 1c). The addition of pyruvate enhanced growth during the recovery period in both strains (Fig. 1c).
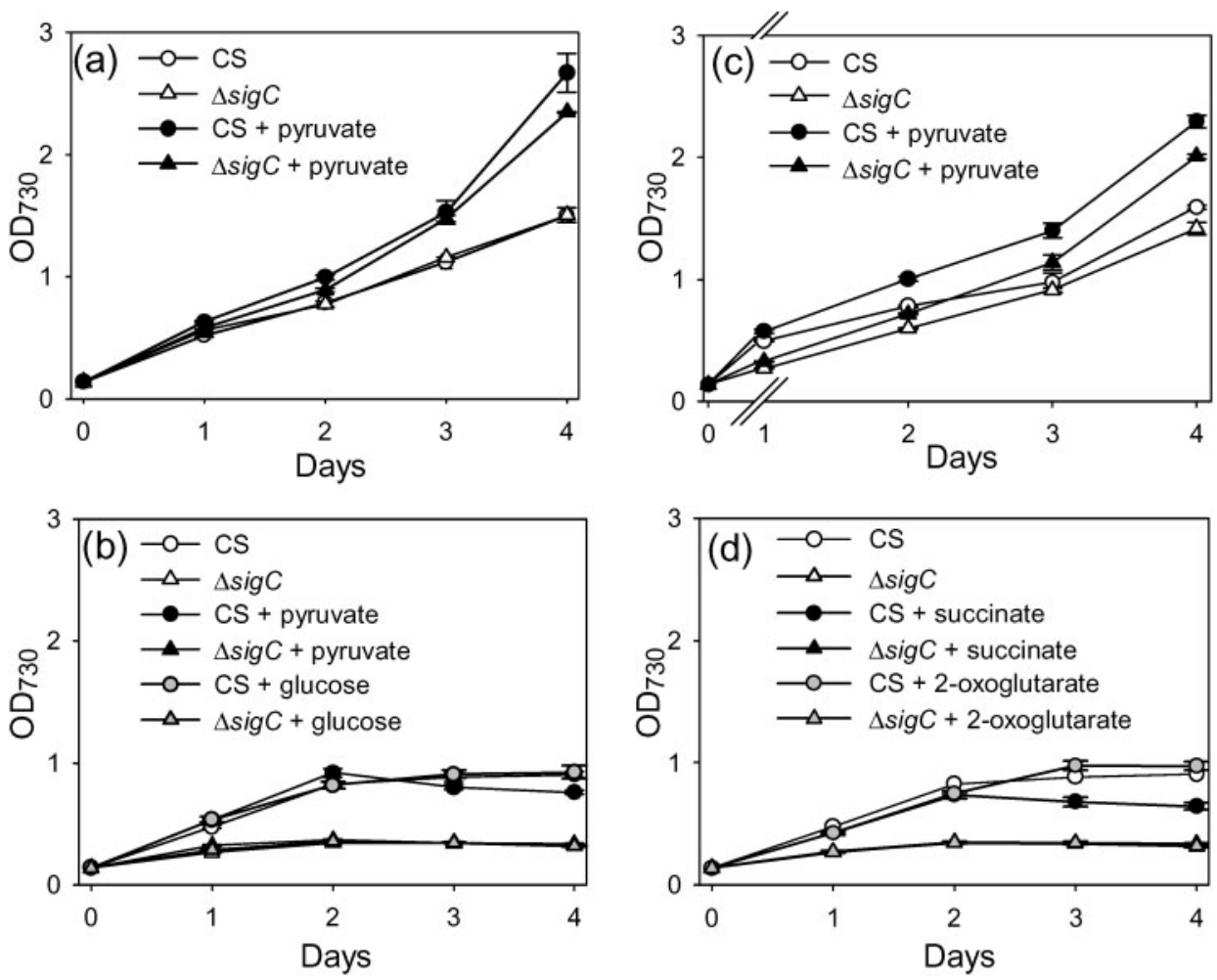

Fig. 1. Effects of organic carbon sources on the growth of Synechocystis PCC 6803 control (CS) and $\Delta$ sigC strains at 32 and $43^{\circ} \mathrm{C}$. (a) The $\mathrm{OD}_{730}$ of the cell cultures was set to 0.14 and the control (circles) and $\Delta$ sigC (triangles) cells were grown in BG-11 medium, pH 7.5, without (white symbols) or with $20 \mathrm{mM}$ pyruvate (black symbols) at $32{ }^{\circ} \mathrm{C}$. (b) The control (circles) and $\Delta$ sigC (triangles) cells were grown at $43{ }^{\circ} \mathrm{C}$ in BG-11 medium, $\mathrm{pH} 7.5$, without additions (white symbols), with $20 \mathrm{mM}$ pyruvate (black symbols) or with $5 \mathrm{~mm}$ glucose (grey symbols). (c) The control (circles) and $\Delta$ sigC (triangles) cells were first grown at $43{ }^{\circ} \mathrm{C}$ for 1 day and thereafter the cultures were transferred to standard growth conditions at $32{ }^{\circ} \mathrm{C}$. Experiments were done with (black symbols) or without (white symbols) addition of $20 \mathrm{mM}$ pyruvate. (d) The control (circles) and $\Delta$ sigC (triangles) cells were grown at $43^{\circ} \mathrm{C}$ in BG-11 medium, $\mathrm{pH} 7.5$, without additions (white symbols), with $20 \mathrm{mM}$ succinate (black symbols) or with $20 \mathrm{mM}$ 2-oxoglutarate (grey symbols). Each growth curve represents the mean of at least three independent experiments and error bars denote SEM. 
To further test the role of low inorganic carbon, we grew the $\Delta$ sigC and control strains in low- $\mathrm{CO}_{2}$ conditions at $32{ }^{\circ} \mathrm{C}$. When the $\mathrm{CO}_{2}$ concentration was lowered to 30 p.p.m., which corresponds to approximately $10 \%$ of the atmospheric concentration, cells grew more slowly than under air-level $\mathrm{CO}_{2}$; at the beginning of the experiments the doubling time was $10.5 \mathrm{~h}$ for both strains under air level $\mathrm{CO}_{2}$, and under low $\mathrm{CO}_{2}$ the doubling time was $21 \mathrm{~h}$ for the control strain and $22 \mathrm{~h}$ for the $\Delta$ sigC strain (Fig. 2a). The $\Delta$ sigC strain grew almost as well as the control strain at the beginning of the low $\mathrm{CO}_{2}$ experiment, but after 3 days the doubling time was $95 \mathrm{~h}$ for the control strain and twice as long, $197 \mathrm{~h}$, for the $\Delta$ sigC strain. Transfer of cells to airlevel $\mathrm{CO}_{2}$ after 6 days in low $\mathrm{CO}_{2}$ reactivated growth, the doubling time being about $35 \mathrm{~h}$ in both strains (Fig. 2b).

Transfer of Synechocystis cells from high- $\mathrm{CO}_{2}$ conditions (3\%) to normal air induces expression of many genes
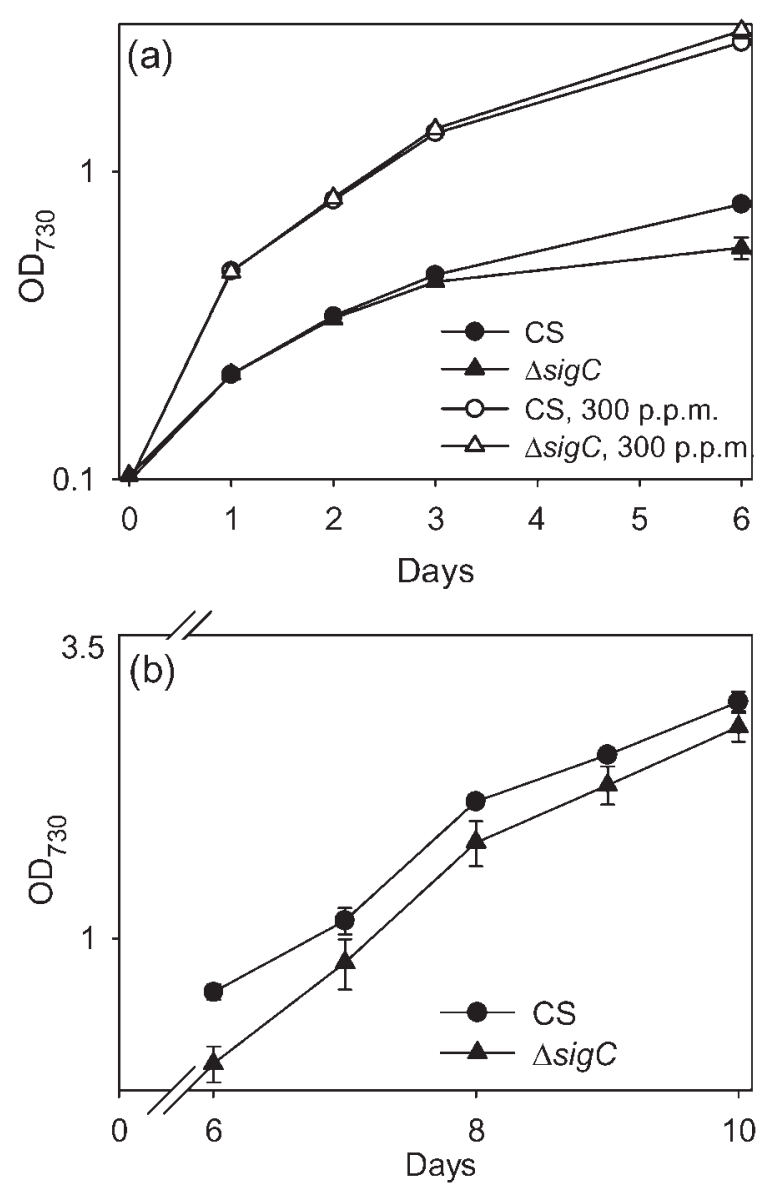

Fig. 2. Growth of control (CS) and $\Delta$ sigC strains under low $\mathrm{CO}_{2}$. (a) The control (circles) and $\Delta$ sigC (triangles) cells were grown under the PPFD of $40 \mu \mathrm{mol} \mathrm{m} \mathrm{m}^{-2} \mathrm{~s}^{-1}$ at $32{ }^{\circ} \mathrm{C}$ under normal air (open symbols) or air containing only 30 p.p.m. $\mathrm{CO}_{2}$ (filled symbols). (b) The control (circles) and $\Delta$ sigC (triangles) cells were first grown for 6 days under low- $\mathrm{CO}_{2}$ conditions, and thereafter cells were transferred to standard conditions for 4 days. involved in carbon-concentrating mechanisms (Wang et al., 2004). In accordance with the lower availability of inorganic carbon at high temperatures, many of these genes are activated when cells are transferred from 32 to $43{ }^{\circ} \mathrm{C}$ (Tuominen et al., 2008). Cyanobacteria can actively take up both $\mathrm{CO}_{2}$ and $\mathrm{HCO}_{3}^{-}$using distinct inorganic carbon acquisition systems, some of which function constitutively and some of which are upregulated at low carbon concentrations (Ogawa \& Kaplan, 2003). Inactivation of the two $\mathrm{CO}_{2}$ uptake systems and three $\mathrm{HCO}_{3}^{-}$uptake systems in the $\Delta 5$ mutant strain of Synechocystis results in a strain that does not show $\mathrm{CO}_{2}$ or $\mathrm{HCO}_{3}^{-}$uptake activity, does not grow under normal air, but grows in high- $\mathrm{CO}_{2}$ conditions (Xu et al., 2008). However, deficiencies in the carbon-concentrating mechanisms are unlikely to explain the poor growth of the $\Delta$ sigC strain at $43{ }^{\circ} \mathrm{C}$, as DNA microarray analyses have shown that the mRNAs for all known proteins of carbon-concentrating mechanisms are at least as abundant in the $\Delta$ sigC strain as in the control strain (Tuominen et al., 2008).

The Synechocystis mutant strain $\Delta 0776$, which contains an inactivated $s p k D$ gene encoding a serine/threonine kinase, can grow under normal air only if the growth medium is supplemented with $\mathrm{HCO}_{3}^{-}$(Laurent et al., 2008). Uptake of inorganic carbon, however, functions in the $\Delta 0776$ strain as well as in the control strain. It has been shown that the $\Delta 0776$ strain contains low amounts of intermediates of the tricarboxylic acid (TCA) cycle, and the growth of the $\Delta 0776$ strain is restored if TCA cycle intermediates are added but not if other organic carbon sources such as pyruvate or glucose are added (Laurent et al., 2008). Growth of the $\Delta \operatorname{sigC}$ strain at $43{ }^{\circ} \mathrm{C}$, in turn, was not affected by addition of TCA cycle intermediates, $20 \mathrm{mM}$ succinate or $20 \mathrm{mM}$ 2-oxoglutarate (Fig. 1d). The finding that addition of any organic carbon source did not restore the growth of the $\Delta \operatorname{sigC}$ strain at $43{ }^{\circ} \mathrm{C}$, although supplementing the air in the growth chamber with $3 \%$ $\mathrm{CO}_{2}$ partially did (Tuominen et al., 2008), suggests that the slow growth of the $\Delta$ sigC strain at high temperature is due to deficiencies in photosynthesis, although the reason is more complicated than just slow production of carbon skeletons.

\section{Growth at $43{ }^{\circ} \mathrm{C}$ is dependent on pH}

The $\mathrm{pH}$ of the growth medium remarkably affects the form and amount of available inorganic carbon. We used BG-11 medium buffered to $\mathrm{pH} 6.6,7.5$ or 8.3. By using the dissociation constant of $\mathrm{HCO}_{3}^{-}$of $4.3 \times 10^{-7} \mathrm{~mol} \mathrm{l}^{-1}$, the equilibrium carbon concentrations $\left(\mathrm{CO}_{2}\right.$ plus $\left.\mathrm{HCO}_{3}^{-}\right)$of the growth medium at $\mathrm{pH} 6.7$ and $\mathrm{pH} 8.3$ were calculated to be 0.2 and six times the carbon concentration at $\mathrm{pH} 7.5$, respectively. At alkaline $\mathrm{pH}$, most carbon is in the form of $\mathrm{HCO}_{3}^{-}$, while at $\mathrm{pH} 6.7,46 \%$ of the dissolved carbon is $\mathrm{CO}_{2}$.

In our standard growth medium at $\mathrm{pH} 7.5, \Delta$ sigC cells hardly grew at all at $43{ }^{\circ} \mathrm{C}$, but cells of the control strain 
grew quite well for up to 3 days (Fig. 3a). In the control strain, the amount of SigC diminished on the third day of incubation (Fig. 4). At $\mathrm{pH}$ 6.7, the control strain grew slowly (Fig. 3b) and only a trace amount of SigC protein
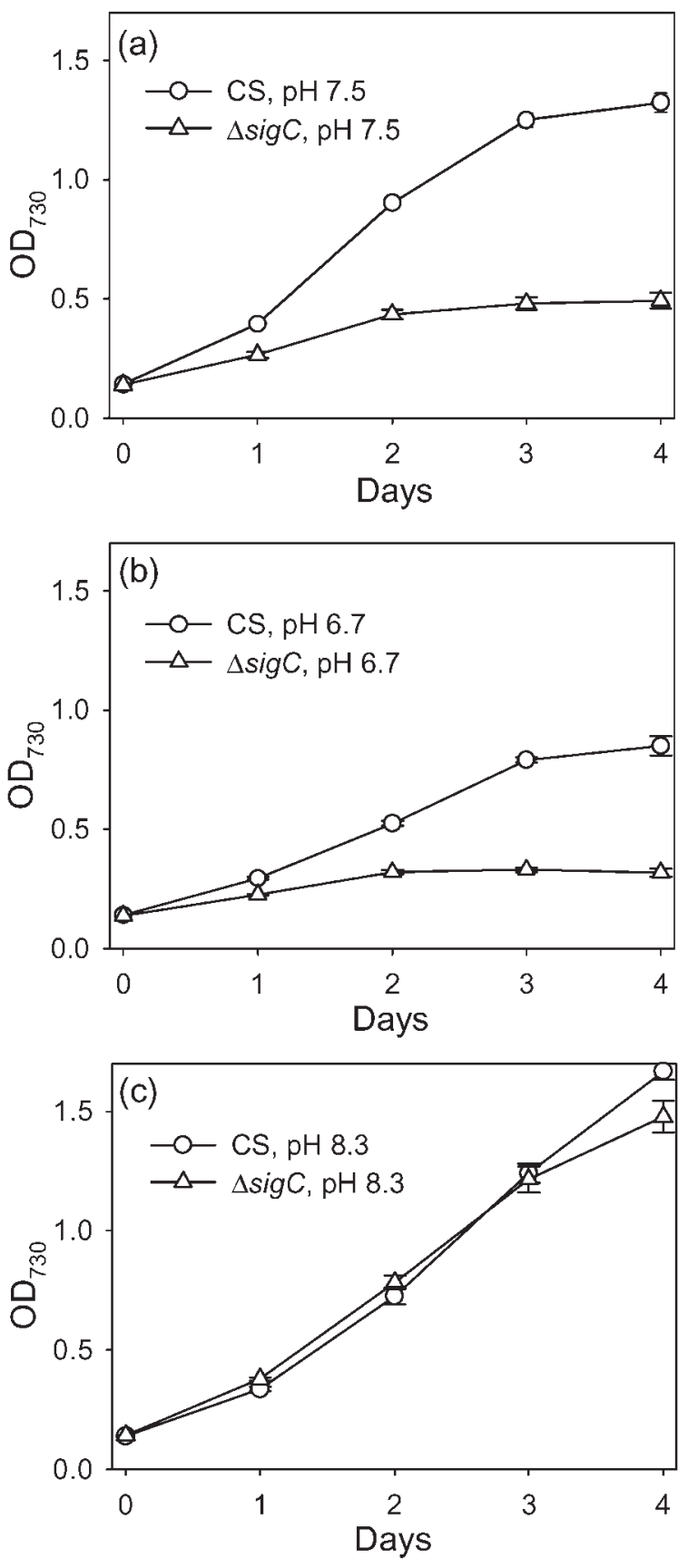

Fig. 3. Growth of the control (CS) and $\Delta$ sigC strains at $43^{\circ} \mathrm{C}$ in BG-11 medium, pH 7.5 (a), $\mathrm{pH} 6.7$ (b) and pH 8.3 (c). The $\mathrm{OD}_{730}$ of the cell cultures was set to 0.14 , and the control (circles) and $\Delta$ sigC (triangles) cells were grown at $43{ }^{\circ} \mathrm{C}$. The BG-11 medium was buffered with $20 \mathrm{mM}$ HEPES- $\mathrm{NaOH}$. Each growth curve represents the mean of five independent experiments and error bars denote SEM. was left after 3 days at $43{ }^{\circ} \mathrm{C}$. These results might indicate that the SigC factor is important for growth when the amount of inorganic carbon, particularly $\mathrm{HCO}_{3}^{-}$, is low. Under alkaline conditions, where more inorganic carbon is available, both the control and the $\Delta$ sigC strains grew well (Fig. 3c). Similarly, the $\Delta$ sigC strain can grow at $43{ }^{\circ} \mathrm{C}$ if the $\mathrm{CO}_{2}$ concentration inside the growth chamber is high (Tuominen et al., 2008).

\section{The $\Delta$ sigC strain contains a low amount of CAMP}

The secondary messenger molecule cAMP is a possible player in the same signalling cascade as the SigC factor, as it was earlier shown that bicarbonate regulates the activity of the adenyl cyclase which generates cAMP in Synechocystis (Masuda \& Ono, 2005). The importance of cAMP for cell motility on agar plates is well characterized in Synechocystis. Inactivation of the adenylate cyclase gene cyal (Terauchi \& Ohmori, 1999) or a cAMP receptor gene sycrp1 (Yoshimura et al., 2002) has been reported to lead to a non-motile phenotype. More recently, three phases were resolved in cell motility and it was reported that the third phase is affected in cyal and sycrp1 mutants (Bhaya et al., 2006). Those authors also showed that the motility of the cyal mutant is restored with the addition of $0.1 \mathrm{mM}$ cAMP. Computational prediction of cAMP receptor protein binding sites suggests that cAMP is involved in the regulation of other cellular processes as well, as putative target genes include photosynthesis, carbon metabolism, transporter and transcription factor genes (Xu \& Su, 2009).

We followed changes in cAMP content at $43{ }^{\circ} \mathrm{C}$ in the control and $\Delta \operatorname{sigC}$ strains. In the $\Delta$ sigC strain, the amount of cAMP was low under standard conditions and after 1,24 and $72 \mathrm{~h}$ treatments at $43{ }^{\circ} \mathrm{C}$ (Fig. 5a). This observation suggests that the SigC factor is involved in the regulation of the cAMP content of the cells. In the control strain, in turn, the amount of cAMP decreased with the incubation time at $43{ }^{\circ} \mathrm{C}$, and after $72 \mathrm{~h}$ incubation, the amount of cAMP had decreased to $13 \%$ of that measured under standard growth conditions. However, addition of $0.1 \mathrm{mM}$ cAMP only slightly activated growth of the $\Delta \operatorname{sigC}$ strain at $43{ }^{\circ} \mathrm{C}$ (Fig. $5 \mathrm{~b}$ ).

\section{Photosynthetic activity of the control and $\Delta$ sigC strains depends on the $\mathrm{pH}$ of the growth medium at $43{ }^{\circ} \mathrm{C}$}

After $1 \mathrm{~h}$ at $43^{\circ} \mathrm{C}$, the photosynthetic activity was approximately three times higher than that measured at $32{ }^{\circ} \mathrm{C}$ in both the control and $\Delta \operatorname{sigC}$ strains, whether the $\mathrm{pH}$ was $6.7,7.5$ or 8.3 (Fig. 6). The measured triple activity of photosynthesis at the beginning of $43{ }^{\circ} \mathrm{C}$ treatment is similar to that reported by Inoue et al. (2001), who found that the photosynthetic activity doubled when the cells were shifted from 32 to $42{ }^{\circ} \mathrm{C}$ and the activity was measured after 5 min.

Analysis of the decay of chl $a$ fluorescence yield after a single-turnover flash indicated that after $1 \mathrm{~h}$ treatment at 


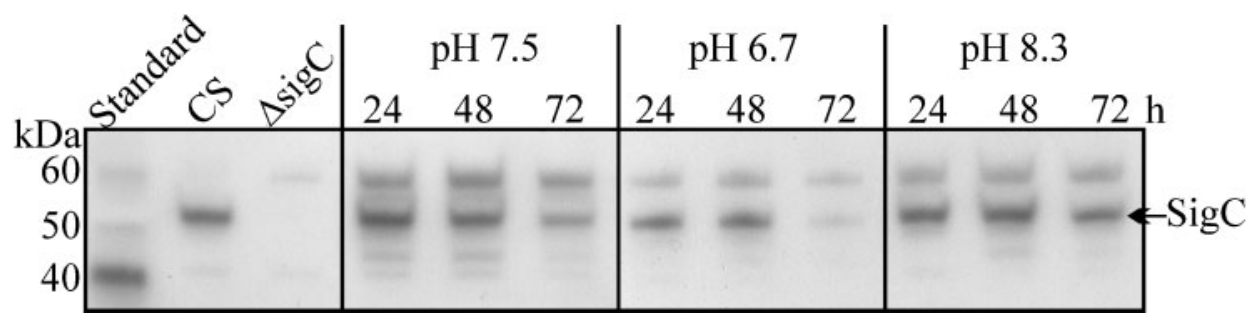

Fig. 4. Amount of the SigC protein. The control (CS) and $\Delta$ SigC strains were grown in $B G-11$ medium, $\mathrm{pH} 7.5$, under standard conditions for $72 \mathrm{~h}$ (leftmost panel). In the three other panels, CS cells were grown at $43{ }^{\circ} \mathrm{C}$ in $\mathrm{BG}-11$ medium buffered with 20 mM HEPES at $\mathrm{pH} 7.5, \mathrm{pH} 6.7$ or $\mathrm{pH} 8.3$ for 24,48 or 72 h prior to protein isolation, as indicated. Proteins were separated by SDS-PAGE, and the amount of SigC protein was determined by Western blotting using a SigC protein specific antibody. The protein standard was MagicMarkXP protein standard (Invitrogen).

(a)
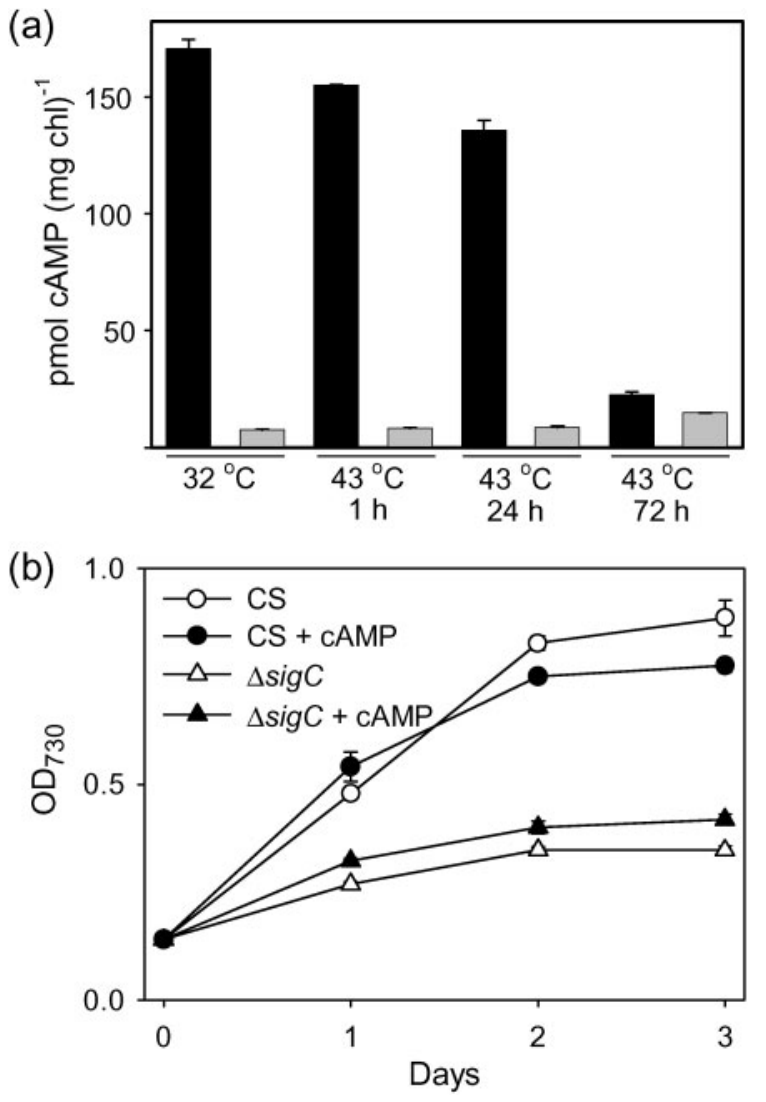

Fig. 5. Secondary messenger cAMP in the control and $\Delta$ sigC strains. (a) Control (black bars) and $\Delta$ sigC (grey bars) cells were treated at standard growth conditions $\left(32{ }^{\circ} \mathrm{C}\right.$ ), and at $43{ }^{\circ} \mathrm{C}$ for 1 , 24 and 72 h. Each bar represents the mean of three independent experiments and error bars denote SEM. (b) The $\mathrm{OD}_{730}$ of the cell cultures was set to 0.14 and the control (CS, circles) and $\Delta$ sigC (triangles) cells were grown at $43^{\circ} \mathrm{C}$ in $\mathrm{BG}-11$ medium without (open symbols) or with $0.1 \mathrm{mM}$ cAMP (filled symbols). Each growth curve represents the mean of three independent experiments and error bars denote SEM.
$43{ }^{\circ} \mathrm{C}$, electron transfer from PSII to the plastoquinone pool was slower than under standard growth conditions. The two fast components reflecting forward electron transport of PSII showed lower amplitudes and slightly longer half times in cells treated for $1 \mathrm{~h}$ at $43{ }^{\circ} \mathrm{C}$ than in cells grown at $32{ }^{\circ} \mathrm{C}$ (Table 1). Thus, changes in the function of PSII do not explain the upregulation of photosynthesis during $1 \mathrm{~h}$ incubation at $43{ }^{\circ} \mathrm{C}$. The increase in light-saturated photosynthetic activity is most probably related to more efficient function of the CalvinBenson cycle at higher temperature.

The photosynthetic activity of the control strain further increased during prolonged growth in BG-11 medium, $\mathrm{pH} 7.5$, at $43{ }^{\circ} \mathrm{C}$, and maximal photosynthetic activity was measured after $18 \mathrm{~h}$ of high-temperature treatment (Fig. 6a). Thereafter, the light-saturated rate of oxygen evolution of the control strain diminished gradually (Fig. 6a). Unlike in the control strain, the light-saturated rate of oxygen evolution of the $\Delta$ sigC strain did not further increase after the first hour at $43{ }^{\circ} \mathrm{C}$; furthermore, the gradual decrease occurred more rapidly, and in the last sample taken after $95 \mathrm{~h}$ at $43{ }^{\circ} \mathrm{C}$, no oxygen evolution was detected in the $\Delta$ sigC strain (Fig. 6a).

When cells were grown in BG-11 medium at pH 6.7 at $43{ }^{\circ} \mathrm{C}$, the light-saturated photosynthetic activity of both the control and the $\Delta$ sigC strains gradually decreased after $1 \mathrm{~h}$ of high-temperature treatment. The loss of photosynthetic activity was faster in the $\Delta$ sigC strain than in the control strain (Fig. 6b). At $\mathrm{pH} 8.3$, in contrast, the lightsaturated photosynthetic activity of both strains remained high throughout the experiment (Fig. 6c). This finding is consistent with the result that both strains were able to grow at $43{ }^{\circ} \mathrm{C}$ if the $\mathrm{pH}$ was 8.3 .

The oxygen-evolving complex of PSII has been shown to be heat sensitive in cyanobacteria (Mamedov et al., 1993). In order to test for known symptoms of damage to the oxygen-evolving complex, we measured the relaxation of fluorescence yield after a single-turnover flash in the presence of the herbicide DCMU. For these experiments, the control and $\Delta$ sigC strains were incubated at $\mathrm{pH} 7.5$ for 

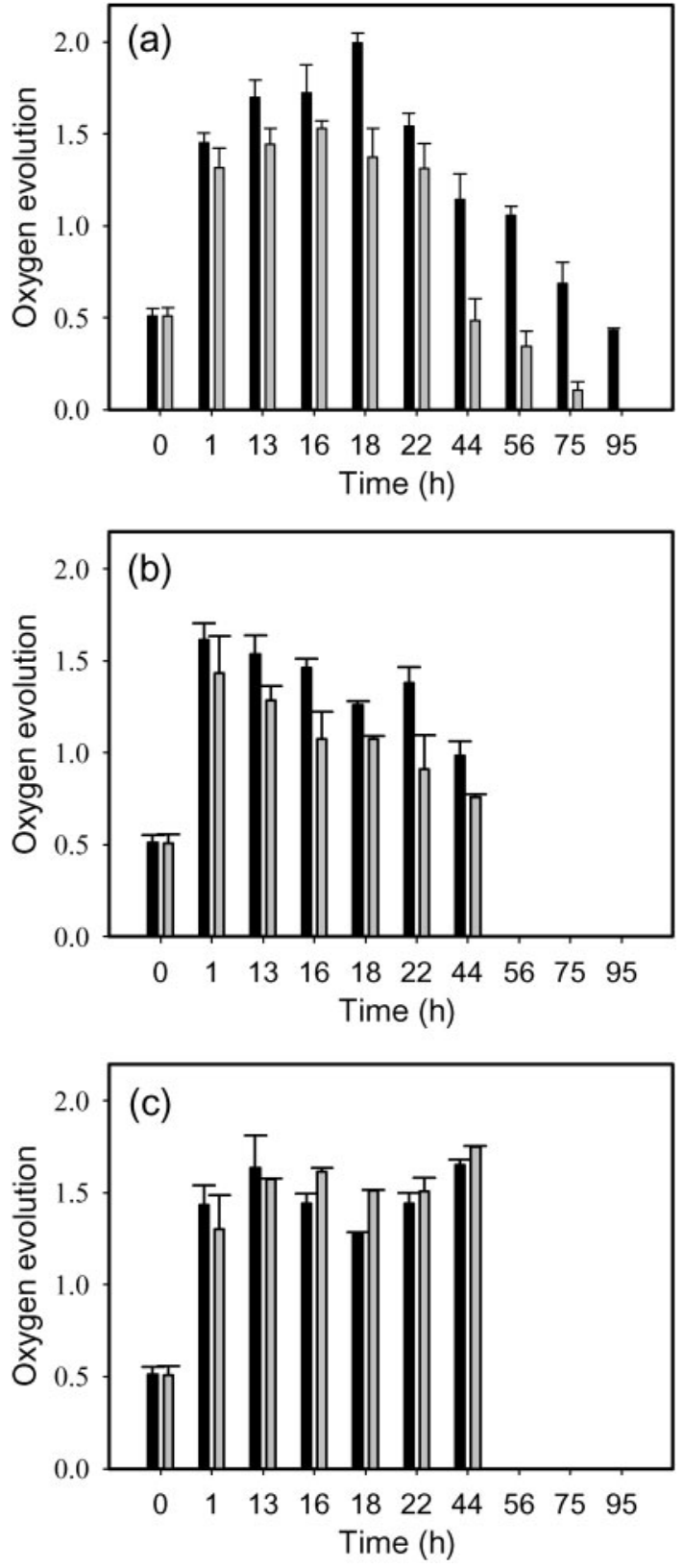

Fig. 6. Changes in the photosynthetic activity of the control and $\Delta$ sigC strains during growth at $43^{\circ} \mathrm{C}$. The control (black columns) and $\Delta$ sigC (grey columns) cells were grown at $43{ }^{\circ} \mathrm{C}$ in BG-11 medium buffered with 20 mM HEPES, pH 7.5 (a), pH 6.7 (b) or $\mathrm{pH} 8.3$ (c). The light-saturated oxygen evolution activity, measured with an oxygen electrode, was calculated as $\mu \mathrm{mol} \mathrm{O}_{2}$ produced $\mathrm{h}^{-1}(\mathrm{ml} \text { cell culture })^{-1}$ at $\mathrm{OD}_{730}=1$. The $0 \mathrm{~h}$ measurement was done at $32{ }^{\circ} \mathrm{C}$. Each bar represents the mean of at least three independent experiments and error bars denote SEM.

1 or $24 \mathrm{~h}$ at $43{ }^{\circ} \mathrm{C}$. If the oxygen-evolving complex is damaged, these measurements are expected to reveal a rapid recombination reaction between $\mathrm{Q}_{\mathrm{A}}^{-}$and oxidized tyrosine D of PSII (Vass et al., 1999). Signs of such a reaction were not seen in the control strain after 1 or $24 \mathrm{~h}$ incubation at $43{ }^{\circ} \mathrm{C}$ (Fig. 7). However, the $\Delta$ sigC strain showed faster initial relaxation of fluorescence yield in the presence of DCMU after $24 \mathrm{~h}$ treatment at $43{ }^{\circ} \mathrm{C}$ (Fig. 7). The signal to noise ratio was low in these data because the amplitude of variable fluorescence was very low after prolonged heat treatment.

Although changes in the activity of the oxygen-evolving complex were not obvious in the control strain, analysis of fluorescence relaxation in the absence of DCMU revealed that moderate heat treatments caused changes in PSII function. The percentage of inactive PSII centres increased from $24 \%$ to $43-47 \%$ in the control strain and from $34 \%$ to $49-51 \%$ in the $\Delta$ sigC strain; this increase occurred at the expense of PSII centres that take part in photosynthetic electron transfer from $\mathrm{Q}_{\mathrm{A}}^{-}$to $\mathrm{Q}_{\mathrm{B}}$ (Table 1). Interestingly, the time constant of the millisecond component of fluorescence relaxation, associated with PSII centres in which the rate of electron transfer from $Q_{A}^{-}$to $Q_{B}$ is limited by the binding of plastoquinone to the $\mathrm{Q}_{\mathrm{B}}$ pocket of PSII, increased substantially during prolonged high-temperature treatment in both strains (Table 1). These data suggest that moderate heat treatment inactivates the binding of plastoquinone to the $\mathrm{Q}_{B}$ pocket in a fraction of PSII centres.

Photosynthesis has been reported to be $\mathrm{pH}$ dependent in some Synechocystis mutants. A mutant lacking proteins of the oxygen-evolving complex of PSII is able to grow at alkaline $\mathrm{pH}$ but not at neutral or acidic $\mathrm{pH}$ (Eaton-Rye et al., 2003). Furthermore, Synechocystis strains $\Delta \mathrm{NdhB}$, with a non-functional $\mathrm{NAD}(\mathrm{P}) \mathrm{H}$ dehydrogenase complex, and $\Delta \mathrm{NdhD} 3 / \mathrm{NdhD} 4$, with an inactivated $\mathrm{CO}_{2}$ uptake system, grow at $\mathrm{pH} 8.3$, but not at $\mathrm{pH} 7.5$ (Zhang et al., 2004).

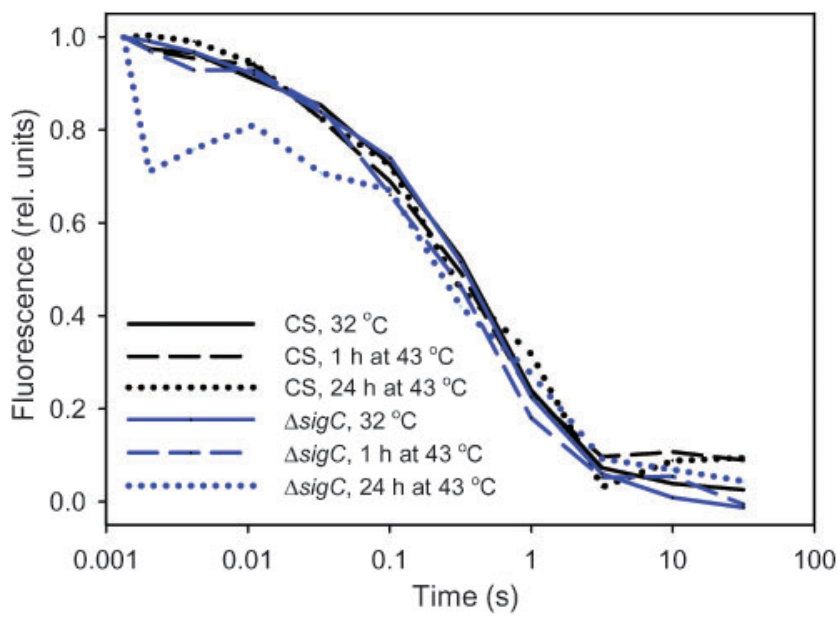

Fig. 7. Relaxation of chl a fluorescence yield after a singleturnover flash in the presence of $10 \mu \mathrm{M}$ DCMU in the control (black) and $\Delta$ sigC (blue) strains. The samples were taken from standard growth conditions (solid line), or after $1 \mathrm{~h}$ (dashed line) or $24 \mathrm{~h}$ (dotted line) treatments at $43^{\circ} \mathrm{C}$. 
Table 1. Flash-induced increase and subsequent decay of chl a fluorescence yield in the control (CS) and $\Delta$ sigC strains, measured from cells grown under standard conditions and after the cells were treated for 1 or $24 \mathrm{~h}$ at $43{ }^{\circ} \mathrm{C}$

Four first-order component reactions were separated, representing populations of PSII in which $\mathrm{Q}_{\mathrm{A}}^{-}$is oxidized by electron transfer to $\mathrm{Q}_{B}$ or $\mathrm{Q}_{\mathrm{B}}^{-}$ (microsecond component), PSII with an empty $\mathrm{Q}_{\mathrm{B}}$ site (millisecond component) and two types of inactive PSII centres, one tentatively oxidizing $\mathrm{Q}_{\mathrm{A}}$ via the recombination reactions $\mathrm{S}_{2 / 3} \mathrm{Q}_{\mathrm{A}}^{-} \rightarrow \mathrm{S}_{1 / 2} \mathrm{Q}_{\mathrm{A}}$ (1-5 s component), another undergoing very slow oxidation of $\mathrm{Q}_{\mathrm{A}}^{-}$, possibly representing inactive PSII in states $\mathrm{S}_{1 / 0} \mathrm{Q}_{\mathrm{A}}^{-}$(component with $\sim 20 \mathrm{~s}$ half-time). The amplitude of the relaxation component is shown as a percentage (\%).

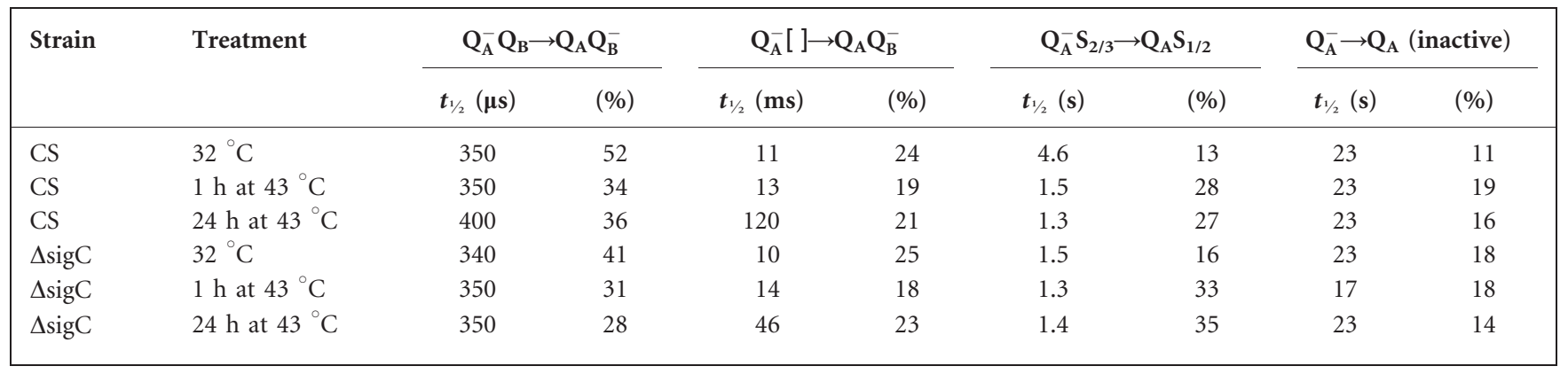

\section{SigC factor is required for survival under unfavourable conditions}

It has been shown that the SigC factor in Synechocystis and its homologue SigE factor in Synechococcus sp. PCC 7002 contribute to gene expression and survival of the cells in the stationary phase (Gruber \& Bryant, 1998; Asayama et al., 2004; Imamura et al., 2006). Inactivation of the sigC gene has been shown to reduce the transcription of the central nitrogen regulatory gene $\operatorname{gn} B$ in stationary phase but not during exponential growth (Asayama et al., 2004). Our results indicate that Synechocystis cells enter stationary phase rapidly at high temperature. However, unlike under standard growth conditions, nitrogen starvation is unlikely to be a central player in induction of the stationary phase at high temperature. Cessation of growth at high temperature occurs so rapidly that nitrogen depletion of the growth medium has not yet occurred, and addition of 2oxoglutarate, which acts as a sensor molecule for nitrogen status (Muro-Pastor et al., 2001b), did not restore growth at $43{ }^{\circ} \mathrm{C}$. Our results point to the involvement of the SigC factor in adjusting photosynthesis at high temperature. Addition of an organic carbon source does not restore the growth of the $\Delta$ sigC strain at high temperatures, although high $\mathrm{CO}_{2}$ or elevated bicarbonate concentrations occurring at high $\mathrm{pH}$ do restore growth, suggesting that photosynthesis as such is important. In addition to linear electron transfer and production of carbon skeletons, photosynthetic electron transfer components are involved in cyclic electron flow around photosystem I (PSI). In cyanobacteria, few different routes for cyclic electron flow have been suggested (Mi et al., 1992; Yeremenko et al., 2005). Cyclic electron flow has turned out to be important under many different stress conditions, including low $\mathrm{CO}_{2}$ and high salt. As the SigC factor seems to be important under many of the same conditions, including low inorganic carbon, as was shown in the present study, or under high salt (Pollari et al., 2008), it might have a regulatory role in cyclic electron flow. This possible connection can be studied in detail after the cyclic electron transfer routes have first been elucidated in detail.

\section{ACKNOWLEDGEMENTS}

Miss Lena Voss is thanked for technical assistance. This work was supported by the Academy of Finland.

\section{REFERENCES}

Asayama, M. \& Imamura, S. (2008). Stringent promoter recognition and autoregulation by the group $3 \sigma$-factor SigF in the cyanobacterium Synechocystis sp. strain PCC 6803. Nucleic Acids Res 36, 52975305.

Asayama, M., Imamura, S., Yoshihara, S., Miyazaki, A., Yoshida, N., Sazuka, T., Kaneko, T., Ohara, O., Tabata, S. \& other authors (2004). $\mathrm{SigC}$, the group 2 sigma factor of RNA polymerase, contributes to the late-stage gene expression and nitrogen promoter recognition in the cyanobacterium Synechocystis sp. strain PCC 6803. Biosci Biotechnol Biochem 68, 477-487.

Bhaya, D., Watanabe, N., Ogawa, T. \& Grossman, A. R. (1999). The role of an alternative sigma factor in motility and pilus formation in the cyanobacterium Synechocystis sp. strain PCC6803. Proc Natl Acad Sci U S A 96, 3188-3193.

Bhaya, D., Nakasugi, K., Fazeli, F. \& Burriesci, M. S. (2006). Phototaxis and impaired motility in adenylyl cyclase and cyclase receptor protein mutants of Synechocystis sp. strain PCC 6803. J Bacteriol 188, 7306-7310.

Eaton-Rye, J. J., Shand, J. A. \& Nicoll, W. S. (2003). pH-dependent photoautotrophic growth of specific photosystem II mutants lacking lumenal extrinsic polypeptide in Synechocystis PCC 6803. FEBS Lett 543, 148-153.

Foster, J. S., Singh, A. K., Rothschild, L. J. \& Sherman, L. A. (2007). Growth-phase dependent differential gene expression in Synechocystis sp. strain PCC 6803 and regulation by a group 2 sigma factor. Arch Microbiol 187, 265-279.

Gruber, T. M. \& Bryant, D. A. (1998). Characterization of the alternative $\sigma$-factors SigD and SigE in Synechococcus sp. strain PCC 7002. SigE is implicated in transcription of post-exponential-phasespecific genes. Arch Microbiol 169, 211-219. 
Huang, L., McCluskey, M. P., Ni, H. \& LaRossa, R. A. (2002). Global gene expression profiles of the cyanobacterium Synechocystis sp. strain PCC 6803 in response to irradiation with UV-B and white light. J Bacteriol 184, 6845-6858.

Imamura, S., Yoshihara, S., Nakano, S., Shiozaki, N., Yamada, A., Tanaka, K., Takahashi, H., Asayama, M. \& Shirai, M. (2003). Purification, characterization, and gene expression of all sigma factors of RNA polymerase in a cyanobacterium. J Mol Biol 325, 857-872.

Imamura, S., Tanaka, K., Shirai, M. \& Asayama, M. (2006). Growth phase-dependent activation of nitrogen-related genes by a control network of group 1 and group $2 \sigma$ factors in a cyanobacterium. J Biol Chem 281, 2668-2675.

Inoue, N., Taira, Y., Emi, T., Yamane, Y., Kashino, Y., Koike, H. \& Satoh, K. (2001). Acclimation to the growth temperature and the high-temperature effects on photosystem II and plasma membranes in a mesophilic cyanobacterium, Synechocystis sp. PCC6803. Plant Cell Physiol 42, 1140-1148.

Kaneko, T., Sato, S., Kotani, H., Tanaka, A., Asamizu, E., Nakamura, Y., Miyajima, N., Hirosawa, M., Sugiura, M. \& other authors (1996). Sequence analysis of the genome of the unicellular cyanobacterium Synechocystis sp. strain PCC 6803. II. Sequence determination of the entire genome and assignment of potential protein-coding regions. DNA Res 3, 109-136.

Laurent, S., Jang, J., Janicki, A., Zhang, C.-C. \& Bédu, S. (2008). Inactivation of $s p k D$, encoding a Ser/Thr kinase, affects the pool of the TCA cycle metabolites in Synechocystis sp. strain PCC 6803. Microbiology 154, 2161-2167.

Lee, S., Owen, H. A., Prochaska, D. J. \& Barnum, S. R. (2000). HSP16.6 is involved in the development of thermotolerance and thylakoid stability in the unicellular cyanobacterium, Synechocystis sp. PCC 6803. Curr Microbiol 40, 283-287.

Mamedov, M., Hayashi, H. \& Murata, N. (1993). Effects of glycinebetaine and unsaturation of membrane lipids on heat stability of photosynthetic electron-transport and phosphorylation reactions in Synechocystis PCC6803. Biochim Biophys Acta 1142, 1-5.

Masuda, S. \& Ono, T.-A. (2005). Adenylyl cyclase activity of Cya1 from the cyanobacterium Synechocystis sp. strain PCC 6803 is inhibited by bicarbonate. J Bacteriol 187, 5032-5035.

Matsui, M., Yoshimura, T., Wakabayashi, Y., Imamura, I., Tanaka, K., Takahashi, H., Asayama, M. \& Shirai, M. (2007). Interference expression at levels of the transcript and protein among group 1, 2, and 3 sigma factor genes in a cyanobacterium. Microbes Environ 22, $32-43$.

Mi, H., Endo, T., Schreiber, U., Ogawa, T. \& Asada, K. (1992). Electron donation from cyclic and respiratory flows to the photosynthetic intersystem chain is mediated by pyridine nucleotide dehydrogenase in the cyanobacterium Synechocystis PCC 6803. Plant Cell Physiol 33, 1233-1237.

Muro-Pastor, A. M., Herrero, A. \& Flores, E. (2001a). Nitrogenregulated group 2 sigma factor from Synechocystis sp. strain PCC 6803 involved in survival under nitrogen stress. J Bacteriol 183, 10901095.

Muro-Pastor, M. I., Reyes, J. C. \& Florencio, F. J. (2001b). Cyanobacteria perceive nitrogen status by sensing intracellular 2oxoglutarate levels. J Biol Chem 276, 38320-38328.

Nakamoto, H., Suzuki, M. \& Kojima, K. (2003). Targeted inactivation of the hcrA repressor gene in cyanobacteria. FEBS Lett 549, 57-62.

Nishiyama, Y., Los, D. A. \& Murata, N. (1999). PsbU, a protein associated with photosystem II, is required for the acquisition of cellular thermotolerance in Synechococcus species PCC 7002. Plant Physiol 120, 301-308.
Ogawa, T. \& Kaplan, A. (2003). Inorganic carbon acquisition systems in cyanobacteria. Photosynth Res 77, 105-115.

Osanai, T., Kanesaki, Y., Nakano, T., Takahashi, H., Asayama, M., Shirai, M., Kanehisa, M., Suzuki, I., Murata, N. \& Tanaka, K. (2005). Positive regulation of sugar catabolic pathways in the cyanobacterium Synechocystis sp. PCC 6803 by the group $2 \sigma$ factor SigE. J Biol Chem 280, 30653-30659.

Osanai, T., Imamura, S., Asayama, M., Shirai, M., Suzuki, I., Murata, N. \& Tanaka, K. (2006). Nitrogen induction of sugar catabolic gene expression in Synechocystis sp. PCC 6803. DNA Res 13, 185-195.

Pollari, M., Gunnelius, L., Tuominen, I., Ruotsalainen, V., Tyystjärvi, E., Salminen, T. \& Tyystjärvi, T. (2008). Characterization of single and double inactivation strains reveals new physiological roles for group $2 \sigma$ factors in the cyanobacterium Synechocystis sp. PCC 6803. Plant Physiol 147, 1994-2005.

Pollari, M., Ruotsalainen, V., Rantamäki, S., Tyystjärvi, E. \& Tyystjärvi, T. (2009). Simultaneous inactivation of sigma factors B and D interferes with light acclimation of the cyanobacterium Synechocystis sp. strain PCC 6803. J Bacteriol 191, 3992-4001.

Singh, A. K., Summerfield, T. C., Li, H. \& Sherman, L. A. (2006). The heat shock response in the cyanobacterium Synechocystis sp. strain PCC 6803 and regulation of gene expression by HrcA and SigB. Arch Microbiol 186, 273-286.

Slabas, A. R., Suzuki, I., Murata, N., Simon, W. J. \& Hall, J. J. (2006). Proteomic analysis of the heat shock response in Synechocystis PCC6803 and a thermally tolerant knockout strain lacking the histidine kinase 34 gene. Proteomics 6, 845-864.

Suzuki, I., Kanesaki, Y., Hayashi, H., Hall, J. J., Simon, W. J., Slabas, A. R. \& Murata, N. (2005). The histidine kinase Hik34 is involved in thermotolerance by regulating the expression of heat shock genes in Synechocystis. Plant Physiol 138, 1409-1421.

Terauchi, K. \& Ohmori, M. (1999). An adenylate cyclase, Cya1, regulates cell motility in the cyanobacterium Synechocystis sp. PCC 6803. Plant Cell Physiol 40, 248-251.

Tuominen, I., Tyystjärvi, E. \& Tyystjärvi, T. (2003). Expression of primary sigma factor (PSF) and PSF-like sigma factors in the cyanobacterium Synechocystis sp. strain PCC 6803. J Bacteriol 185, 1116-1119.

Tuominen, I., Pollari, M., Tyystjärvi, E. \& Tyystjärvi, T. (2006). The SigB sigma factor mediates high-temperature responses in the cyanobacterium Synechocystis sp. PCC6803. FEBS Lett 580, 319-323.

Tuominen, I., Pollari, M., von Wobeser, E. A., Tyystjärvi, E., Ibelings, B. W., Matthijs, H. C. P. \& Tyystjärvi, T. (2008). Sigma factor SigC is required for heat acclimation of the cyanobacterium Synechocystis sp. strain PCC 6803. FEBS Lett 582, 346-350.

Tyystjärvi, E. \& Vass, I. (2004). Light emission as a probe of charge separation and recombination in the photosynthetic apparatus: relation of prompt fluorescence to delayed light emission and thermoluminescence. In Chlorophyll a Fluorescence: a Signature of Photosynthesis, pp. 363-388. Edited by G. C. Papageorgiou \& Govindjee. Dordrecht: Springer.

Vass, I., Kirilovsky, D. \& Etienne, A.-L. (1999). UV-B radiationinduced donor- and acceptor-side modifications of photosystem II in the cyanobacterium Synechocystis sp PCC 6803. Biochemistry 38, 12786-12794.

Wang, H.-L., Postier, B. L. \& Burnap, R. L. (2004). Alterations in global patterns of gene expression in Synechocystis sp. PCC 6803 in response to inorganic carbon limitation and the inactivation of $n d h R$, a LysR family regulator. J Biol Chem 279, 5739-5751.

Wösten, M. M. S. M. (1998). Eubacterial sigma-factors. FEMS Microbiol Rev 22, 127-150. 
Xu, M. \& Su, Z. (2009). Computational prediction of cAMP receptor protein (CRP) binding sites in cyanobacterial genomes. BMC Genomics 10, 23.

Xu, M., Bernát, G., Singh, A., Mi, H., Rögner, M., Pakrasi, H. B. \& Ogawa, T. (2008). Properties of mutants of Synechocystis sp. strain PCC 6803 lacking inorganic carbon sequestration systems. Plant Cell Physiol 49, 1672-1677.

Yeremenko, N., Jeanjean, R., Prommeenate, P., Krasikov, V., Nixon, P. J., Vermaas, W. F. J., Havaux, M. \& Matthijs, H. C. P. (2005). Open reading frame ssr2016 is required for antimycin A-sensitive photosystem I-driven cyclic electron flow in the cyanobacterium Synechocystis sp. PCC 6803. Plant Cell Physiol 46, 1433-1436.

Yoshimura, H., Yoshihara, S., Okamoto, S., Ikeuchi, M. \& Ohmori, M. (2002). A cAMP receptor protein, SYCRP1, is responsible for the cell motility of Synechocystis sp. PCC 6803. Plant Cell Physiol 43, 460-463.

Zhang, P., Battchikova, N., Jansen, T., Appel, J., Ogawa, T. \& Aro, E.-M. (2004). Expression and functional roles of the two distinct NDH-1 complexes and the carbon acquisition complex NdhD3/NdhF3/CupA/ Sll1735 in Synechocytis sp PCC 6803. Plant Cell 16, 3326-3340.

Edited by: A. Wilde 